\title{
A ABORDAGEM PESSOANA DOS TEMAS GRECO-LATINOS CLÁSSICOS EM RICARDO REIS
}

\author{
Maristella Gabardo ${ }^{1}$
}

"Reis is the nearest that Pessoa could come to being Caeiro. A disciple of Caeiro, Reis works paganism into anethical doctrine, part epicurean, part stoic, yet concious of, and kept clear of, a human environment conditioned by christianity; a doctrine for pleople in the modern world to live by, so as to suffer as little as possible." 2

Jonathan Griffin

As influências clássicas de Ricardo Reis se tornam evidentes desde a escolha pelo formato Ode (canção) para seu poemas até a apropriação dos grandes temas clássicos, utilizados em discussões centrais de sua obra.

Reis busca a simetria de versos (normalmente utilizando dez sílabas poéticas nos versos longos e seis poéticas nos versos curtos), também, a musicalidade de seus versos suscita dúvidas sobre o uso explícito ou não de rimas em seus poemas.

"Sim, sei bem

Que nunca serei alguém.

Sei de sobra

Que nunca terei uma obra.

Sei, enfim,

Que nunca saberei de mim.

Sim, mas agora,

Enquanto dura essa hora,

Este luar, estes ramos,

Esta paz em que estamos,

Deixem-me me crer

$O$ que poderei ser."

Neste poema o heterônimo faz uso de três dos instrumentos que possibilitam sua poesia, explicitado-os nas Páginas Íntimas e de Auto-Interpretação:

"Há um novo meio exterior além da palavra, para projetar a idéia em palavras através da emoção. Esse meio é o ritmo, a rima e a estrofe"

"Quanto mais fria a poesia mais verdadeira. A emoção não deve entrar na poesia senão como elemento dispositivo do ritmo, que é a sobrevivência longínqua da música no verso."

\footnotetext{
${ }^{1}$ Gradução Letras-UFPR.

${ }^{2}$ Pessoa, Fernando. Galaxy of Poets. Lisboa. 1985

${ }^{3}$ Pessoa, Fernando. Odes. Se. Sd. P. 133.
}

80 
E em seus poemas:

"Ponha na altiva mente o fixo esforço

Da altura, e à sorte deixo,

E as suas leis, o verso;

Que, quando é alto e régio o pensamento,

Súbita a frase o busca

E o scravo ritmo serve". 4

A música para Reis seria somente emoção, enquanto a poesia, só idéias, e o canto, uma junção dos dois.( $\left(1^{\circ}\right.$ : ponto- depois, espaço) Isso inevitavelmente conduz à recordação de que a poesia era indissociada da música, cantada, nos períodos clássicos da Grécia. Ali, na poesia antiga, se unia a emoção às idéias, na voz do Aedo ou cantor/poeta lírico.

A sua forma de escrita elevada, com composições simétricas, se enlaça perfeitamente com a escrita latinizante utilizada em seus versos:

"Bem sei, ó Flava, que inda" ( Flava, do latim Flavus ou loiro),

ou como

"Tarda o que spera, e é nada"

"Um branco som de spuma"

Outro ponto expressivo é que a maioria das musas que aparecem em Ricardo Reis são encontradas (s/ vírgula após sujeito) também em Horácio, como Lídia ou Cloe. O racional CARPE DIEM e a brevidade da vida :

"Colhe o dia, porque és ele." 5

Um dos aspectos clássicos que chamam muita atenção dentro da arca de pensamentos de Reis é o uso da expressão CARPE DIEM, que foi verbalizada por Horácio na Ode Ad Leuconoen (ODE1.11).

"Tu ne quaesieris (scirenefas) quem mihi, quem tibi

Finem di dederint, Leuconoe, nec Babylonios

Temptaris numeros.Ut melius quicquid erit pati!

Seu pluris hiemes seu tribuit Iuppiter ultimam

${ }^{4}$ Odes, p 158

${ }^{5}$ Odes, p154 
Quae nunc oppositis debilitat pumicibus mare

Tyrrhenum, sapies, uina liques et spatio breui

Spem longam reseces. Dumloquimur, fugerit inuida

Aetas: carpe diem, quam minimum credula postero". ${ }^{6}$

Nesta Horácio expõe o conceito de "aproveite" ou "colha o dia"(não seria melhor pôr entre aspas, já que são "conceitos"?) de uma forma moderada, sem exacerbações, num equilíbrio natural típico da 'aurea mediocritas' que norteia seu fazer poético. Diferente de algumas acepções posteriores de Carpe Diem, como, por exemplo, a utilizada por alguns poetas barrocos que pregavam o Carpe Diem como o uso máximo do dia, cheio de emoções, aventuras e exacerbações. Vejamos os poema de Reis:

"Vem sentar-te comigo, Lídia, à beira do rio.

Sossegadamente fitemos o seu curso e aprendamos

Que a vida passa, e não estamos de mãos enlaçadas.

(enlacemos as mãos)

(...)

Desenlacemos as mãos, porque não vale a pena cansarmo-nos.

Que gozemos, quer não gozemos, passamos como o rio.

Mais vale saber passar silenciosamente

E sem desassossegos grandes.

Sem amores, nem ódios, nem paixões que levantam a voz,

Nem invejas que dão movimento demais aos olhos,

Nem cuidados, porque se os tivesse o rio sempre correria,

E sempre iria ter ao mar". ${ }^{7}$

Neste poema vê-se clara a influência estóica de Sêneca, (1 ${ }^{\text {o: }}$ vírgula- depois, espaço)que vê a morte como um fato natural, consequiência do nascimento.

VII 3-4: "Deve-se aprender a viver por toda a vida e, por mais que tu talvez te espantes, (não haveria uma vírgula aqui?) a vida toda é um aprender a morrer" 8

Isso, em Reis, também se explicita em:

\section{"Não há tristezas}

Nem alegrias

Na nossa vida.

Assim saibamos,

\footnotetext{
${ }^{6}$ Achcar, Francisco. Lírica e Lugar-comum alguns temas de Horácio. E sua presença em português. Edusp. SãoPaulo.1994

${ }^{7}$ Odes, p23

${ }^{8}$ Sêneca, Sobre a Brevidade da vida

82
} 
Sábios incautos,

Não a viver,

Mas decorrê-la,

Tranqüilos, plácidos,

Tendo as crianças

Por nossas mestras,

E os olhos

Cheios

De natureza...

À beira-rio

À beira-estrada,

Conforme calha.

Sempre no mesmo

Leve descanso

De estar vivendo". 9

Nos poemas acima se acentua mais uma vez o Carpe Diem . Nunca, porém, o extremo. Isto é, o heterônimo analisa se vale a pena ceder às paixões e emoções, se a vida segue sempre para um fim certo, assim como um rio que corre para o mar .

"Quer gozemos, quer não gozemos, passamos como o rio"

"Colhamos flores, pega tu nelas e deixa-as no colo, e que o seu perfume suavize o momento"

A imagem, da flor marca, aqui, assim como na tradição clássica, a brevidade da vida.

"Coroai-me de rosas,

Coroai-me em verdade

De rosas-

Rosas que se apagam

Em fronte a apagar-se

Tão cedo!

Coroai-me de rosas

$E$ de folhas breves

E basta". ${ }^{10}$

\section{O ideal filosófico}

${ }^{9}$ Odes, p 13

${ }^{10}$ Odes,p18 
"Ocorreu-me a idéia e a tornar (filosofia) um neoclassicismo "científico"(...) reagir contra duas correntes- tanto contra o romantismo moderno, como contra o neoclassicismo à Maurras(...)"

A filosofia estóica em geral tem como princípio a aproximação com a natureza. Esta é permeada de Racionalidade e bondade, matéria sobre a ação da razão. Sendo assim, pela cópia da natureza, o homem deve ser bom e racional. A flor nasce, tem o seu auge, dura 2 ou 3 dias e desfalece. O homem também, se não souber ser bom e racional, isto é, viver dentro da moral, terá a impressão de que teve pouco tempo de ápice, e inicio(?) o seu esvair-se, Não alcançando a ataraxia.

II 1 : "Por que nos queixamos da Natureza? Ela mostrou-se benevolente, a vida, se souberes utiliza-la, é longa"12

Essa visão de passagem do tempo como algo inevitável (vírgula depois de sujeito...) faz um contraponto (tudo junto)com a visão clássica, que considera a velhice como algo muitas vezes ultrajante e não belo. A própria passagem do tempo para a o ideal heróico grego é distinta, pois esta marca o tempo, ou a sua passagem e a sua importância, não só por ciclos cronológicos, mas pela quantidade de feitos heróicos realizados .

Sendo assim, o único conhecimento filosófico necessário é o de que morreremos um dia; por isso só a flor basta (retomando o pensamento clássico para o qual a flor simboliza a brevidade da vida), "Coroai-me, coroai-me de rosas, de flores e de folhas breve ." Esta é a principal função da filosofia na análise estóica, um fio condutor para ensinar a viver - e (por que não?) a morrer, já que a morte é uma consequiência natural da vida.

“As rosas dos jardins de Adónis, essas volucres amo, Lídia, rosas, que em o dia em que nascem, em esse dia morrem.

A luz para elas é eterna, porque

Nascem nascido já o Sol, acabam Antes que Apolo deixe

O seu curso visivel.

Assim façamos nossa vida um dia. Inscientes, Lídia, voluntariamente

Que há noite antes e após

$O$ pouco que duramos." 13

\footnotetext{
"Lind, Rudolf Georg e Coelho, Jacinto de Prado. Páginas Íntimas e de Auto InterpretaçãoFernando Pessoas. Ática. Lisboa

${ }^{12}$ Sêneca, Sobre a Brevidade da vida

${ }^{13}$ Odes. P34

84
} 
A análise que Sêneca ${ }^{14}$ faz do oráculo de Delfos é exatamente esta. "CONHECE-TE A TI MESMO" diz respeito à tomada da consciência pelas pessoas de que são mortais e, por isso, com limites, o que as leva a atingir o conhecimento pleno de si próprio.

"Em paga nobre desta fé que temos na exilada verdade dos seus corpos nos dão o alto prêmio de nos deixarem ser"

\section{Paganismo}

O paganismo clássico também faz parte da retórica de Ricardo Reis.

" $O$ deus Pã não morreu, cada campo que mostra aos sorrisos de Apolo os peitos nus de CeresCedo ou tarde vereis Por lá aparecer $O$ deus Pã, o imortal.

Não matou outros deuses $O$ triste deus cristão.

Cristo é um deus a mais, Talvez um que faltava. Pã continua a dar Os sons de sua flauta Aos ouvidos de Ceres Recumbente nos campos.(...) "15

No poema acima afirma-se a existência de vários deuses, inclusive a de Cristo, que não é negada, mas colocada (concorda c/ "existência") no paganismo tardio de Reis como integrante de um grupo pré-existente de divindades, 'O deus triste' que faltava ao panteão.

"Não a ti, Cristo, odeio ou te não quero.

Em ti como nos outros creio deuses mais velhos

Só te tenho por Não mais nem menos

Do que eles, mas mais novo apenas.

${ }^{14}$ Sêneca, Sobre a Brevidade da vida

${ }^{15}$ Odes, p 19 
Odeio sim, e a esses com calma aborreço

Que te querem acima dos outros teus iguais deuses.

Quero-te onde tu stás, nem mais alto

Nem mais baixo que eles, tu apenas.

$(\ldots)^{\prime \prime 16}$

Trabalha com o mesmo tipo de imagens do universo mitológico religioso grecolatino, no qual os deuses não prestam atenção ao homem e nem o protegem das parcas.

"Sob a tutela

de deuses descuidosos, quero gastar as concedidas horas desta fadada vida.

Nada podendo contra O ser que me fizeram, Desejo ao menos que me haja o Fado Dado a paz por destino.

Da verdade não quero Mais que a vida; que os deuses Dão vida e não verdade nem talvez Saibam qual a verdade. $" 17$

Pois, assim como no pensamento pagão-clássico, os deuses estão abaixo do destino (juntamente com todos os demais), subjugados a ele:

\footnotetext{
Como acima dos deuses o Destino

É calmo e inexorável,

Acima de nós-mesmos construamos

Um fado voluntário

Que quando nos oprima nós sejamos

Esse que nos oprime,

E quando entremos pela noite dentro

Por nosso pé entremos. "18
}

Isto contraria o pensamento clássico: a idéia de que o covarde não participa de guerras e batalhas, tornando-se socialmente vergonhoso para as famílias e para a

${ }^{16}$ Odes, p72

${ }^{17}$ Odes, p173

${ }^{18}$ Odes, p 41

86 
nação. Este amor à pátria acima de tudo e o heroísmo de morrer lutando pela terra $\mathrm{e}$ pelo povo, assim como qualquer amor, contrariam o seu inerente e característico desapego, (mudança de sujeito: vírgula)e por isto são negado por Ricardo Reis :

\section{"Prefiro rosa, meu amor, à pátria"}

E afinal, negando a paixão, o amor exacerbado, ele se aproxima da ataraxia. Ricardo Reis, não só nega todas as paixões que o afastam do ideal ataráxico, como demonstra um desapego a ( $\mathrm{s} /$ crase)tudo que não conduz a ele, o que é peculiar ao paganismo estóico.

"Segue o teu destino,
rega as tuas plantas,
ama as tuas rosas.
O resto é a sombra
De árvores alheias.

\section{A realidade}

Sempre é mais ou menos

Do que nós queremos.

Só nós somos sempre

Iguais a nós - próprios

... 19

"Tudo, desde ermos astros afastados

A nós, nos dá o mundo.

E a tudo, alheios, nos acrescentamos,

Pensando e interpretando.

A próxima erva a que não chega basta,

O que há é melhor." 20

O conceito clássico de beleza, no qual tudo o que é verdadeiro é bom e belo. Então era muito comum que para que fossem retiradas as máscaras que normalmente as pessoas usavam, fosse utilizado (ou "se utilizasse") o vinho, que além de deixar as pessoas verdadeiras, suavizava a brevidade das coisas.

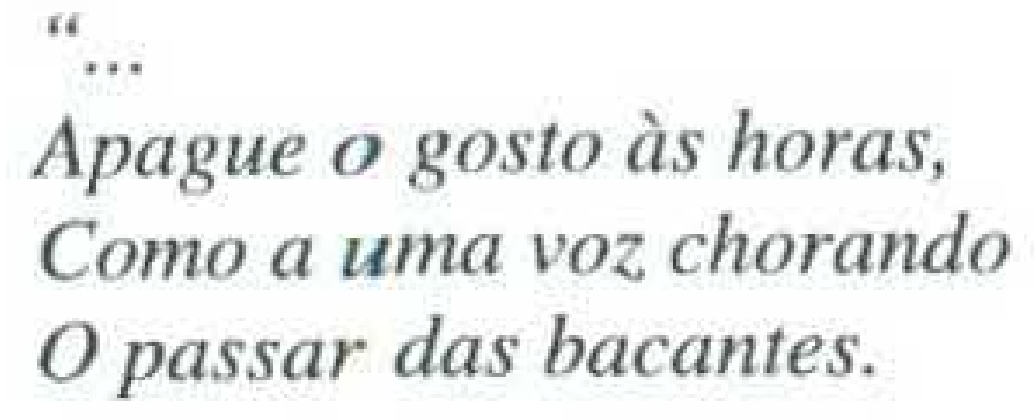

\footnotetext{
${ }^{19}$ Odes, p 68

${ }^{20}$ Odes, p136
} 
E ele espera, contente quase e bebedor tranqüilo,

E apenas desejando

Num mal tido

Que a abominável onda

O não molhe tão cedo."

\section{Por que (separado...) escrever ?}

"Em seus poemas (de Ricardo Reis) repetem-se (vírgula separando sujeito do restante d oração, não) verbos no imperativo, o que sugere que o seu discurso fala de desejo e não de vivência. Pretende convencer o outro, mas também precisa dessa pedagogia, o que indica que o seu descentramento (não seria assim?)de si mesmo é um artifício irônico e uma busca de solução para o fato de não ter ele um ponto de referência, de certeza em que se apoie."

Ainda se vê (advérbio atrai pronome oblíquo)uma possível influência do também clássico Alberto Caieiro na poesia de Ricardo Reis, pois este, assim como o primeiro, não questiona a sua própria existência.

"Os deuses são deuses porque não pensam"

A busca pela inconsciência como condição de felicidade, causada, provavelmente, pelo descentramento do homem na realidade existencial do séc. XX, leva o poeta a se exilar do universo cultural numa ordem natural, propondo a fuga para $\mathrm{o}$ antigo:

"à beira- rio

à beira - estrada

conforme calha

sempre no mesmo

leve descenso

de estar vivendo" ${ }^{, 23}$

Assim o poeta tenta acalmar a sua alma pela poesia.

Odes, p33

${ }^{22}$ Meller, Vilson Brunel e Pinto, Sérgio de Castro .Fernando Pessoa Estudos Críticos Associação Federal da Paraíba. João Pessoa-Brasil. 1985 Artigo : Simulacro e Consciência irônica em Fernando Pessoa de Lélia Parreira Duarte ${ }^{23}$ Odes, p 13

88 


\section{Referências Bibliograficas:}

Montalvor, Luís de. Odes de Ricardo Reis. Coleção Poesia (IV). Editora Ática, Lisboa. 1981

Meller, Vilson Brunel e Pinto, Sérgio de Castro. Fernando Pessoa Estudos Críticos. Associação Federal da Paraíba. João Pessoa- Brasil. 1985

Lind, Rudolf Georg e Coelho, Jacinto de Prado. Páginas Íntimas e de Auto Interpretação-Fernando Pessoas. Ática. Lisboa

Achcar, Francisco. Lírica e Lugar-comum alguns temas de Horácio. E sua presença em português. Edusp. SãoPaulo.1994

Pessoa, Fernando. Galaxy of Poets. Lisboa. 1985

Pereira, Maria helena da Rocha. Novos Ensaios sobre temas Clássicos na poesia Portuguesa. Imprensa Nacional.

Rebelo, Luís de Sousa. A Tradição Clássica na Literatura Portuguesa. Horizonte Universitário. Lisboa.1982

Fernando Pessoa: as muitas águas de um rio. Pioneira: novos umbrais. Editora da universidade de São Paulo- São Paulo. 1987

Lind, Georg Rudolf. Estudos sobre Fernando Pessoa. Estudos Portugueses. Imprensa Nacional.

Diversidade e Unidade em Fernando Pessoa. Quarta edição. Editorial Verbo. Lisboa1980

Seabra, José Augusto. Fernando Pessoa ou a Poetodrama. Estudos/Crítica. Editora Perspectiva. Segunda edição. São Paulo-1991

Simões, João Gaspar. Vida e obra de Fernando Pessoa - História de uma Geração . Livraria Bertrand- Segunda Edição

Nery, Pe. J. de Castro. Evolução do Pensamento Antigo. Segunda Edição. Livraria do globo

Nicola, José de. Infante, Ulisses. Como ler Fernando Pessoa. Editora Scipione. Terceira Edição. São Paulo.[19-] 
Pessoa, Fernando. Fiç̧ões do Interlúdio/2-3 Editora Nova Fronteira.

Quesado, José Clécio Basílio. O constelado de Fernando Pessoa- A objetivação da subjetividade em, Ricardo Reis. Imago Editora. Rio de Janeiro. 1976

Guntert, Georges. Reconciliação Estética num mundo irreconciliável: Ricardo Reis. S..[19-] 